\title{
Heteroatom and solvent effects on molecular properties of formaldehyde and thioformaldehyde symmetrically disubstituted with heterocyclic groups $\mathrm{C}_{4} \mathrm{H}_{3} \mathrm{Y}$ (where $\mathrm{Y}=\mathrm{O}-\mathrm{Po}$ )
}

\author{
${\text { Piotr } \text { Matczak }^{1} \text { (D) } \cdot \text { Malgorzata Domagala }}^{1}$
}

Received: 20 June 2017 / Accepted: 28 July 2017 /Published online: 21 August 2017

(C) The Author(s) 2017. This article is an open access publication

\begin{abstract}
In this work several molecular properties of symmetrically disubstituted formaldehyde and thioformaldehyde have been studied using a quantum chemistry approach based on density functional theory. Five-membered heteroaromatic rings containing a single group 16 heteroatom were taken into account as the substituents (i.e., furan-2-yl, thiophen-2-yl, selenophen-2-yl, tellurophen-2-yl, and the experimentally as yet unknown polonophen-2-yl). For the resulting ten formaldehyde and thioformaldehyde derivatives, the geometry, energetics, frontier molecular orbitals, dipole moment and polarizability of their molecules were examined in order to establish the effect of ring heteroatom on these properties. Furthermore, these properties were also determined for the molecules in three solvents of low polarity (benzene, chloroform, and dichloromethane) in order to expand our study to include solvent effects. The dipole moment and polarizability of the investigated molecules show regular variations when the ring heteroatom descends through group 16 and the solvent polarity grows. The heteroatom and/or solvent effects on the part of the studied properties are, however, more complex. An attempt is made to rationalize the observed variations in the molecular properties. The conformational behavior of the investigated molecules was also explored and the
\end{abstract}

Electronic supplementary material The online version of this article (doi:10.1007/s00894-017-3435-4) contains supplementary material, which is available to authorized users.

Piotr Matczak

p.a.matczak@gmail.com

1 Department of Theoretical and Structural Chemistry, Faculty of Chemistry, University of Łódź, Pomorska 163/165, 90-236 Lodz, Poland conformationally weighted values of dipole moment and polarizability are presented.

Keywords Quantum chemical calculations · Molecular properties · Five-membered heterocyclic substituents · Group 16 heteroatoms

\section{Introduction}

Organic molecules containing heterocyclic fragments constitute one of the most important research areas in modern organic, bioorganic and medicinal chemistry [1-3]. The importance of such molecules is reflected in their innumerable applications, at both laboratory and industrial scale. A reason for this importance arises from the possibility of modifying existing functions or imparting new desired features to organic molecules through the introduction of one or more heteroatoms into their cyclic fragments. The presence of heteroatoms in the resulting heterocyclic fragments leads to the redistribution of electron density and changes in possible aromatic character [4], which allows for the manipulation of various molecular properties, such as reactivity, optoelectronic properties, chelating ability and many others. These properties may be strongly affected by the occurrence of a heteroatom in a heterocyclic fragment, and by the kind of heteroatom introduced. This is usually referred to as the heteroatom effect. In the case of molecules with substituents being five-membered aromatic monocycles with a single group 16 heteroatom (furan, thiophene, selenophene, tellurophene), it is known that the heteroatom effect is responsible for changes in their properties that respond to many demands relevant to organic synthesis [5-7], optics [8-10], electronics [11], material science [12], pharmacology [13] and biology [14]. If such molecules are in solution, the surrounding solvent usually exerts an 
additional influence on their properties. For instance, the dependence of their reactivity $[6,15]$, conformational preference [16-18], reaction kinetics [19] or spectroscopic properties [20, 21] on the presence of a solvent and its polarity has been detected.

In this work, a set of ten molecules representing symmetrically disubstituted formaldehyde and thioformaldehyde is the subject of a quantum chemical investigation of their molecular properties. Five-membered heterocyclic substituents $\mathrm{C}_{4} \mathrm{H}_{3} \mathrm{Y}$ containing a single group 16 heteroatom $\mathrm{Y}$ (furan-2$\mathrm{yl}$ for $\mathrm{Y}=\mathrm{O}$, thiophen-2-yl for $\mathrm{Y}=\mathrm{S}$, selenophen-2-yl for $\mathrm{Y}=\mathrm{Se}$, tellurophen-2-yl for $\mathrm{Y}=\mathrm{Te}$, and the experimentally as yet unknown polonophen-2-yl for $\mathrm{Y}=\mathrm{Po}$ ) are taken into account. The resulting two series of formaldehyde and thioformaldehyde derivatives, also termed here symmetrical diheteroaryl ketones and thioketones, are interesting from both theoretical and experimental points of view. In general, they are useful for the synthesis of other important organic compounds $[7,22,23]$. The preparative perspective also reveals their mutual connection. Such thioketones can be prepared from corresponding ketones via oxygen/sulfur exchange, as has very recently been carried out using Lawesson's reagent [24]. Here, the geometry, energetics, frontier molecular orbitals, dipole moment and polarizability in vacuum and in solvents, were obtained for the aforementioned two series of molecules, using a density functional theory method and an implicit solvation model. Tracking variations in these properties along the two series of molecules allowed us to establish how strongly these properties are linked with the kind of ring heteroatom and the presence of solvent. To the best of our knowledge, there are only sparse computational studies that include an analysis of heteroatom and/or solvent effects for some symmetrical diheteroaryl ketones and thioketones $[17,25,26]$. In the case of the title compounds, only molecules with light ring heteroatoms (most often with sulfur) have been studied using quantum chemical methods so far $[17,20,21,26-28]$. This work extends our previous computational study of symmetrical diheteroaryl ketones and thioketones [26] to the full range of group 16 ring heteroatoms, and, additionally, it includes the effect of solvent.

\section{Computational details}

The molecular geometries of five symmetrical diheteroaryl ketones (1a-5a, see Scheme 1) and their thiocarbonyl analogs (1b-5b) were optimized in vacuum at the RI-B3LYP/def2QZVPP level of theory [29-33]. The obtained geometries of isolated molecules were subsequently optimized in the presence of a solvent, using RI-B3LYP/def2-QZVPP and the COSMO implicit solvation model [34]. Three solvents of low polarity, in terms of both their dipole moment and dielectric constant, were considered. In order of increasing polarity,

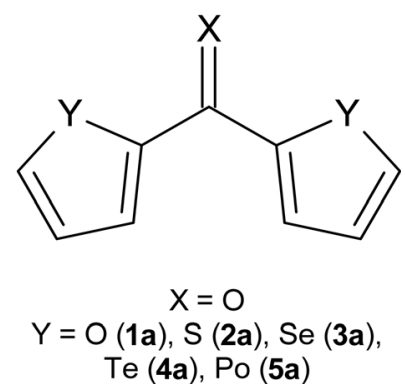

Scheme 1 Symmetrically disubstituted formaldehyde 1a-5a

these solvents are benzene, chloroform, and dichloromethane. Our interest in solvents of low polarity arises from their frequent use in the synthesis and reactions of diheteroaryl ketones and thioketones [24]. Harmonic vibrational frequency calculations yield no imaginary frequencies for all the optimized molecular geometries. For the molecules containing heavy atoms, such as Te in $\mathbf{4 a}$ and $\mathbf{4 b}$, and Po in $\mathbf{5 a}$ and $\mathbf{5 b}$, the inner electrons of these atoms are modeled by the Stuttgart effective core potentials $[35,36]$ provided with the def2QZVPP basis set. The $[\mathrm{Ar}] 3 d^{10}$ inner electrons of Te and the $[\mathrm{Kr}] 4 d^{10} 4 f^{14}$ inner electrons of Po are replaced with the Stuttgart effective potentials. The application of these effective core potentials allows for the inclusion of scalar relativistic effects in the geometry optimizations of $\mathbf{4 a}, \mathbf{4 b}, \mathbf{5 a}$, and $\mathbf{5 b}$. Such a one-component treatment of relativity should be sufficient for obtaining molecular geometries with reasonable accuracy, because scalar relativistic effects are usually much more important for geometries than spin-orbit relativistic effects $[37,38]$. However, an accurate determination of energetics for molecules with heavy atoms requires a computational treatment accounting for spin-orbit coupling. Therefore, the final total energies of $\mathbf{4 a}, \mathbf{4} \mathbf{b}, \mathbf{5 a}$, and $\mathbf{5 b}$ have been recalculated at the two-component relativistic RI-B3LYP/ dhf-QZVPP-2c level of theory [39, 40]. The sizes of Te and Po cores described by the dhf-QZVPP-2c effective potentials are the same as those defined by def2-QZVPP. The calculations of molecular dipole moments, average static dipole polarizabilities, and polarizability anisotropies were carried out using the aforementioned levels of theory. In addition, the def2-QZVPP and dhf-QZVPP-2c basis sets were augmented with a small number of moderately diffuse functions recommended for efficient computations of electronic response properties [41]. Test calculations performed for a set of small molecules with structural features occurring in $\mathbf{1 a - 5 a}$ and $\mathbf{1 b}$ $\mathbf{5 b}$ confirm that the use of these diffuse functions does improve the accuracy of the predicted molecular dipole moments and polarizabilities (see sections S1 and S2 in the Electronic Supplementary Material).

The selection of B3LYP for this work was originally based on the well-known good performance of this density functional in predicting geometries and energies [42]. The accurate prediction of electric properties is generally a more difficult 
challenge for B3LYP, with its performance then depending on which electric property is calculated and what class of molecules is considered [43, 44]. There are several benchmark studies that report a relatively good performance of B3LYP for calculating low-order ground-state electric properties such as dipole moment and polarizability [45-47]. The results of our test calculations from section S2 also indicate the satisfactory performance of B3LYP for molecular dipole moments and polarizabilities in a set of small molecules with structural features occurring in $\mathbf{1 a}-\mathbf{5 a}$ and $\mathbf{1} \mathbf{b}-\mathbf{5} \mathbf{b}$.

All calculations were carried out using TURBOMOLE (versions 6.5 and 7.0.1) [48]. Contours of frontier molecular orbitals were visualized using TmoleX 4.1 [49].

\section{Results and discussion}

\section{Molecular geometry and stability}

The molecules of the investigated compounds can adopt three conformations, differing in the orientation of ring heteroatoms $(\mathrm{Y}=\mathrm{O}-\mathrm{Po})$ relative to the carbonyl oxygen atom $(\mathrm{X}=\mathrm{O})$ in $\mathbf{1 a}-\mathbf{5 a}$ or the thiocarbonyl sulfur atom $(X=S)$ in $\mathbf{1 b}-\mathbf{5 b}$. The first type of conformation exists if $\mathrm{X}$ and both $\mathrm{Y}$ atoms are on the same side of the $\mathrm{C}-\mathrm{C}$ bonds linking the heteroaryl substituents with the $\mathrm{C}=\mathrm{X}$ group. In other words, both $\mathrm{Y}$ atoms display a cis-like orientation with respect to the $\mathrm{X}$ atom. The resulting conformer will be denoted here by the prefix $c c$. The trans-like orientation of $\mathrm{X}$ relative to $\mathrm{Y}$ of both heteroaryl rings leads to the $t t$-conformer. Finally, the third type of conformation combines a X,Y-cis-like orientation for one heteroaryl ring and a X,Y-trans-like orientation for another ring. The $c t$ and $t c$-conformers are regarded to be identical due to disubstitution with the same heteroaryl group. In other words, the third type of conformation refers to two degenerate structures (a schematic visualization of possible conformations is presented in Scheme 2). Torsion angles $\tau$ formed by three consecutive bonds in the $\mathrm{X}=\mathrm{C}-\mathrm{C}-\mathrm{Y}$ fragments are suitable geometrical parameters for characterizing the three conformations. Due to its symmetrical molecular geometry, each $c c$ and $t t$-conformer possesses a pair of identical $\tau$ twist angles. The values of $\tau$ for all conformers of $\mathbf{1 a}-\mathbf{5 a}$ and $\mathbf{1 b}-\mathbf{5 b}$ are shown in Tables 1 and 2 .

The replacement of $\mathrm{Y}=\mathrm{O}$ by a heavier group 16 heteroatom leads to a gradual increase in the twist angle of heteroaryl substituents relative to the $\mathrm{C}=\mathrm{X}$ group for the $t \mathrm{t}$-conformers in vacuum. Their $\tau$ values become smaller with the growing atomic radius of $\mathrm{Y}$, which means that the substituents are more and more distorted from coplanarity with the $\mathrm{C}=\mathrm{X}$ group. The same trend in $\tau$ is observed for the trans-like heteroaryl ring of $c t$-conformers. The cis-like heteroaryl ring displays less regular changes in $\tau$ but the total inclination between the planes of both heteroaryl rings still grows while $\mathrm{Y}$ descends

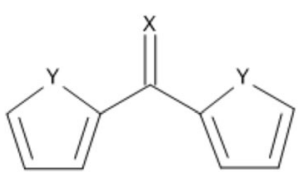

CC

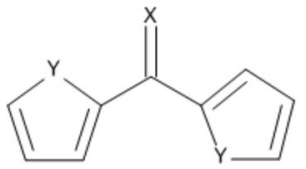

$c t$

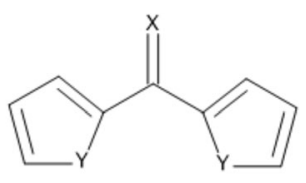

$t t$

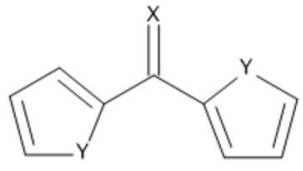

tc

$$
\begin{gathered}
X=O, S \\
Y=O, S, S e, \text { Te, Po }
\end{gathered}
$$

Scheme 2 Schematic representation of possible conformations for molecules $\mathbf{1 a}-\mathbf{5 a}$ and $\mathbf{1 b}-\mathbf{5 b}$

through group 16. For the $c c$-conformers, the replacement of oxygen by a heavier $Y$ heteroatom results in irregular changes of $\tau$. In this case, keeping balance between some additional subtle effects, such as intramolecular $\mathrm{X} \cdots \mathrm{Y}$ and $\mathrm{H} \cdots \mathrm{H}$ interactions [28], may be decisive.

The presence of a solvent essentially strengthens the effect of Y on $\tau$, if compared to the corresponding $\tau$ values detected for the $c t$ - and $t t$-conformers in vacuum. The resulting solvent effect is, however, rather minor: the inclination between the planes of heteroaryl rings in the solvated $c t$ - and $t t$-conformers grows by merely several degrees. The solvent effect does not hold for $c t$-1a and $t t-\mathbf{1 a}$, which retain their planar geometry in solvents. The inclination between the planes of heteroaryl rings is usually augmented by the increase of solvent polarity. $\mathbf{1 a}, \mathbf{1 b}, \mathbf{2} \mathbf{a}$, and $\mathbf{2} \mathbf{b}$ in the $c c$-conformation show, however, the reverse relationship between the inclination of heteroaryl rings and the solvent dielectric constant $\varepsilon$.

The relative stability of individual conformers of the investigated compounds was established using the differences $\Delta G$ in the Gibbs free energies of the conformers at 298.15 K. For each compound, its most stable conformer is characterized by $\Delta G=0$, whereas those possessing higher (i.e., less negative) Gibbs free energies than the preferred conformer demonstrate $\Delta G>0$. An inspection of the $\Delta G$ values presented for the isolated molecules in Tables 1 and 2 reveals that the $c t$-conformation is the most energetically favorable if $\mathrm{Y}=\mathrm{O}$. Unlike $\mathbf{1 a}$ and $\mathbf{1 b}$, all the remaining compounds prefer the $c c$-conformation, while their $t t$-conformers are least stable. The growing atomic radius of $Y$ along the series $\mathbf{2 a}-\mathbf{5 a}$ and $\mathbf{2 b}-\mathbf{5 b}$ results in increases of $\Delta G$ for the $c t$ - and $t t$-conformers. For that reason, the compounds with $\mathrm{Y}=\mathrm{Te}$, Po exhibit negligible percentage abundances of their $t t$-conformers relative to the $c c$-conformers (the conformer abundances are based on the Boltzmann distribution of conformers in their equilibrium mixture at $298.15 \mathrm{~K}$; see section S1). The preferred conformers of the investigated compounds usually make dominant contributions to the corresponding equilibrium mixtures 
Table 1 Twist angles between the $\mathrm{X}$ and $\mathrm{Y}$ atoms of the $\mathrm{X}=\mathrm{C}-\mathrm{C}-\mathrm{Y}$ fragments $\left(\tau\right.$ in $\left.{ }^{\circ}\right)$ and relative Gibbs free energies $\left(\Delta G\right.$ in $\left.\mathrm{kcal}_{\mathrm{mol}}{ }^{-1}\right)$ for the conformers of $\mathbf{1 a}-\mathbf{5 a}$ in vacuum and solvents

\begin{tabular}{|c|c|c|c|c|c|c|c|c|}
\hline \multirow[t]{3}{*}{ Conformer } & \multicolumn{8}{|l|}{ Medium } \\
\hline & \multicolumn{2}{|l|}{ Vacuum } & \multicolumn{2}{|l|}{ Benzene } & \multicolumn{2}{|l|}{ Chloroform } & \multicolumn{2}{|c|}{ Dichloromethane } \\
\hline & $\tau$ & $\Delta G^{\mathrm{a}}$ & $\tau$ & $\Delta G^{\mathrm{a}}$ & $\tau$ & $\Delta G^{\mathrm{a}}$ & $\tau$ & $\Delta G^{\mathrm{a}}$ \\
\hline$c c-\mathbf{1 a}$ & -17.7 & $2.84[0.3]$ & -17.0 & $2.17[1.1]$ & -16.5 & $1.76[2.3]$ & -16.1 & $1.43[4.0]$ \\
\hline$c t-\mathbf{1 a}$ & $0.0(179.9)$ & $0.00[80.7]$ & $0.0(179.9)$ & $0.00[87.8]$ & $0.0(179.9)$ & $0.00[88.8]$ & $0.0(179.9)$ & 0.00 [89.0] \\
\hline$t t-\mathbf{1 a}$ & 180.0 & $0.45[19.0]$ & 180.0 & $0.81[11.1]$ & 180.0 & $0.95[9.0]$ & 180.0 & $1.09[7.0]$ \\
\hline$c c-\mathbf{2} \mathbf{a}$ & -18.6 & $0.00[38.8]$ & -18.5 & $0.00[44.1]$ & -18.4 & $0.00[49.7]$ & -18.2 & $0.00[53.2]$ \\
\hline$c t-2 \mathbf{a}$ & $-15.9(157.9)$ & $0.17[58.4]$ & $-16.6(157.2)$ & $0.30[53.3]$ & $-16.9(156.9)$ & 0.43 [48.2] & $-17.1(156.7)$ & 0.51 [44.9] \\
\hline$t t-\mathbf{2 a}$ & 159.2 & $1.56[2.8]$ & 158.0 & $1.67[2.6]$ & 157.4 & $1.85[2.2]$ & 157.2 & $2.00[1.8]$ \\
\hline$c c-\mathbf{3 a}$ & -18.1 & $0.00[66.7]$ & -18.7 & $0.00[68.8]$ & -19.0 & $0.00[68.8]$ & -19.1 & $0.00[71.3]$ \\
\hline$c t-\mathbf{3 a}$ & $-16.1(154.6)$ & $0.84[32.6]$ & $-16.8(154.0)$ & 0.89 [30.5] & $-17.2(153.7)$ & $0.89[30.5]$ & $-17.4(153.6)$ & $0.96[28.0]$ \\
\hline$t t-\mathbf{3 a}$ & 155.9 & $2.73[0.7]$ & 154.9 & $2.70[0.7]$ & 154.3 & $2.73[0.7]$ & 154.1 & $2.79[0.6]$ \\
\hline$c c-\mathbf{4 a}$ & -17.0 & $0.00[90.3]$ & -17.5 & $0.00[87.7]$ & -17.8 & $0.00[86.3]$ & -18.0 & $0.00[85.2]$ \\
\hline$c t-\mathbf{4 a}$ & $-15.3(150.4)$ & $1.74[9.6]$ & $-16.3(149.8)$ & 1.58 [12.1] & $-16.9(149.5)$ & $1.51[13.5]$ & $-17.3(149.5)$ & $1.46[14.5]$ \\
\hline$t t-\mathbf{4 a}$ & 152.4 & $4.16[0.1]$ & 151.1 & $3.82[0.1]$ & 150.5 & $3.58[0.2]$ & 150.2 & $3.46[0.2]$ \\
\hline$c c-\mathbf{5} \mathbf{a}$ & -16.7 & $0.00[95.2]$ & -17.8 & 0.00 [93.9] & -18.5 & $0.00[92.3]$ & -19.0 & $0.00[90.8]$ \\
\hline$c t-\mathbf{5 a}$ & $-14.8(148.6)$ & $2.19[4.7]$ & $-15.7(147.8)$ & $2.03[6.1]$ & $-16.4(147.4)$ & $1.89[7.6]$ & $-16.9(147.3)$ & $1.78[9.0]$ \\
\hline$t t-\mathbf{5 a}$ & 151.1 & $4.80[0.0]$ & 149.7 & $4.34[0.1]$ & 149.2 & $4.01[0.1]$ & 148.9 & $3.77[0.2]$ \\
\hline
\end{tabular}

${ }^{\mathrm{a}}$ The percentage abundances of individual conformers in the equilibrium mixture of three conformers of each compound are shown in square brackets

of three conformers. The lowest percentage abundances of the preferred conformer are found for $\mathbf{2 a}$ and $\mathbf{2 b}(38.8 \%$ and
$48.8 \%$, respectively), which results from the small $\Delta G$ values of their $c t$-conformers.

Table 2 Twist angles between the $\mathrm{X}$ and $\mathrm{Y}$ atoms of the $\mathrm{X}=\mathrm{C}-\mathrm{C}-\mathrm{Y}$ fragments $\left(\tau\right.$ in $\left.{ }^{\circ}\right)$ and relative Gibbs free energies $\left(\Delta G\right.$ in kcal mol $\left.{ }^{-1}\right)$ for the conformers of $\mathbf{1 b}-\mathbf{5 b}$ in vacuum and solvents

\begin{tabular}{|c|c|c|c|c|c|c|c|c|}
\hline \multirow[t]{3}{*}{ Conformer } & \multicolumn{8}{|l|}{ Medium } \\
\hline & \multicolumn{2}{|l|}{ Vacuum } & \multicolumn{2}{|l|}{ Benzene } & \multicolumn{2}{|l|}{ Chloroform } & \multicolumn{2}{|c|}{ Dichloromethane } \\
\hline & $\tau$ & $\Delta G^{\mathrm{a}}$ & $\tau$ & $\Delta G^{\mathrm{a}}$ & $\tau$ & $\Delta G^{\mathrm{a}}$ & $\tau$ & $\Delta G^{\mathrm{a}}$ \\
\hline$c c-\mathbf{1 b}$ & -21.4 & $2.58[0.6]$ & -21.0 & $1.70[2.5]$ & -20.6 & $1.27[5.2]$ & -20.2 & $0.99[8.2]$ \\
\hline$c t-\mathbf{1 b}$ & $-6.4(172.5)$ & $0.00[89.9]$ & $-7.8(170.4)$ & $0.00[87.2]$ & $-8.4(169.5)$ & $0.00[88.0]$ & $-8.5(169.3)$ & $0.00[86.9]$ \\
\hline$t t-1 \mathbf{b}$ & 164.5 & $0.92[9.5]$ & 164.5 & $0.85[10.3]$ & 164.8 & $1.10[6.9]$ & 165.0 & $1.29[4.9]$ \\
\hline$c c-\mathbf{2} \mathbf{b}$ & -22.8 & $0.00[49.3]$ & -22.8 & $0.00[53.1]$ & -22.7 & $0.00[56.3]$ & -22.7 & $0.00[58.5]$ \\
\hline$c t-\mathbf{2 b}$ & $-21.5(149.7)$ & $0.42[48.8]$ & $-21.9(149.6)$ & $0.51[45.1]$ & $-22.2(149.7)$ & $0.58[42.1]$ & $-22.3(149.9)$ & $0.63[40.1]$ \\
\hline$t t-2 \mathbf{b}$ & 150.6 & $1.92[1.9]$ & 150.2 & $2.00[1.8]$ & 150.1 & $2.11[1.6]$ & 150.1 & $2.21[1.4]$ \\
\hline$c c-\mathbf{3 b}$ & -22.2 & $0.00[67.4]$ & -22.5 & $0.00[67.6]$ & -22.6 & $0.00[68.4]$ & -22.6 & $0.00[70.2]$ \\
\hline$c t-\mathbf{3 b}$ & $-19.9(146.3)$ & $0.85[31.9]$ & $-20.7(146.5)$ & $0.86[31.5]$ & $-21.2(146.7)$ & $0.88[30.7]$ & $-21.4(147.0)$ & $0.93[29.0]$ \\
\hline$t t-\mathbf{3 b}$ & 148.9 & $2.71[0.7]$ & 148.2 & $2.62[0.8]$ & 147.9 & $2.61[0.8]$ & 147.8 & $2.66[0.8]$ \\
\hline$c c-\mathbf{4 b}$ & -20.6 & $0.00[89.2]$ & -21.0 & $0.00[87.2]$ & -21.3 & $0.00[85.7]$ & -21.4 & $0.00[84.7]$ \\
\hline$c t-\mathbf{4 b}$ & $-16.2(141.2)$ & $1.67[10.7]$ & $-17.3(141.6)$ & $1.55[12.7]$ & $-18.2(142.2)$ & $1.48[14.1]$ & $-18.8(142.5)$ & $1.43[15.1]$ \\
\hline$t t-4 b$ & 146.9 & $4.24[0.1]$ & 146.1 & $3.87[0.1]$ & 145.9 & $3.62[0.2]$ & 145.8 & $3.45[0.3]$ \\
\hline$c c-\mathbf{5 b}$ & -20.3 & 0.00 [92.9] & -21.0 & $0.00[91.5]$ & -21.8 & $0.00[88.8]$ & -22.1 & $0.00[86.3]$ \\
\hline$c t-5 \mathbf{b}$ & $-15.0(139.2)$ & $1.93[7.1]$ & $-16.1(139.5)$ & $1.82[8.4]$ & $-17.1(140.1)$ & $1.65[11.0]$ & $-17.8(140.6)$ & $1.51[13.5]$ \\
\hline$t t-5 \mathbf{b}$ & 146.6 & $4.64[0.0]$ & 146.4 & $4.18[0.1]$ & 146.4 & $3.79[0.1]$ & 146.5 & $3.49[0.2]$ \\
\hline
\end{tabular}

${ }^{a}$ The percentage abundances of individual conformers in the equilibrium mixture of three conformers of each compound are shown in square brackets 
The presence of a solvent essentially does not change the sequences of conformers ordered relative to their stability. Such a solvent effect occurs for all the investigated compounds with one exception. For $\mathbf{1 b}$ solvated in dichloromethane, the sequence of higher-energy conformers is swapped, compared to the ordering of such conformers in vacuum and in two solvents of lower polarity. The solvent effect on the percentage abundances of preferred conformers is non-uniform, with both increases and decreases in abundance observed while the solvent polarity is growing. For instance, the percentage abundance of $c t-\mathbf{1} \mathbf{a}$ is enhanced in polar solvents, whereas the opposite situation is observed for $c t-\mathbf{1} \mathbf{b}$. Nevertheless, a general finding can be made that an increase in the solvent polarity leads to an additional stabilization of $c c$ conformation for $\mathbf{1 a}-\mathbf{3 a}$ and $\mathbf{1} \mathbf{b}-\mathbf{3 b}$. In consequence, the percentage abundances of these $c c$-conformers go up while the solvent varies from benzene to chloroform and then to dichloromethane. The solvents produce the reverse effect on the $c c$ conformation of $\mathbf{4 a}, \mathbf{4 b}, \mathbf{5 a}$, and $\mathbf{5 b}$. For these compounds, their $c t$-conformers experience an effective stabilization by the solvents with higher $\varepsilon$. This is accompanied by the corresponding increases in the percentage abundances of $c t$-conformers at the expense of $c c$-conformer abundances.

\section{Frontier molecular orbitals}

Among frontier molecular orbitals, the highest occupied molecular orbital (HOMO) and the lowest unoccupied molecular orbital (LUMO) are particularly important in describing intrinsic molecular properties. Therefore, it is interesting to inspect the heteroatom and solvent effects on the HOMO and LUMO of $\mathbf{1 a}-\mathbf{5 a}$ and $\mathbf{1 b}-\mathbf{5 b}$.

Figure 1 presents the plots of HOMO and LUMO contours for a part of the investigated molecules. The molecules shown in this figure are selected in a way that allows us to detect trends in the heteroatom effect. For 1a-3a, their HOMO shows a purely $\pi$ character and it is delocalized over the heteroaryl substituents. The HOMO of the ketones with heavier ring heteroatoms $(\mathrm{Y}=\mathrm{Te}, \mathrm{Po})$ possesses substantial contributions from the $\sigma$-based orbitals belonging to these heteroatoms, and a minor share of X-atom lone pair orbital. The LUMOs of all ketones demonstrate common features. The contribution of the $\pi^{*}$ orbital of carbonyl group predominates and the LUMOs also spread over the $\pi^{*}$-type orbitals of heteroaryl substituents. In the case of the thioketones, their HOMO is centered mainly on the $\mathrm{S}$ atom of the thiocarbonyl group. In addition to the lone pair orbital of this $\mathrm{S}$ atom, the heavier ring heteroatoms $(\mathrm{Y}=\mathrm{Te}, \mathrm{Po})$ also provide notable contributions to the HOMO. The LUMO of $\mathbf{1 b}-\mathbf{5 b}$ is fairly similar to that of the ketones.

Figure 2 presents the HOMO and LUMO levels of the isolated $c c$-conformers. The difference between the HOMO and LUMO levels, i.e., the HOMO-LUMO energy gap, is

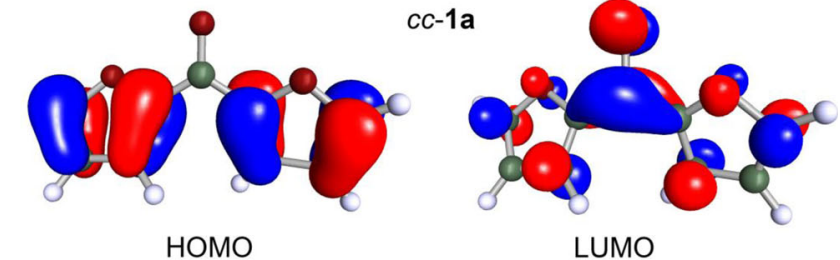

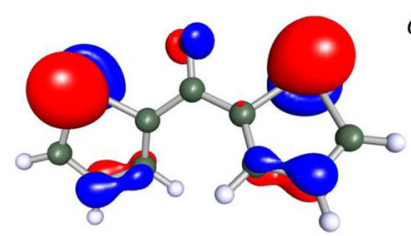

HOMO

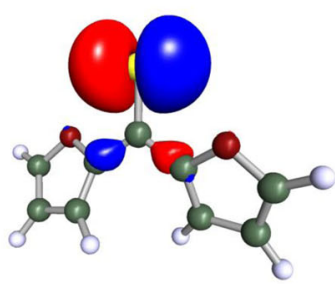

HOMO

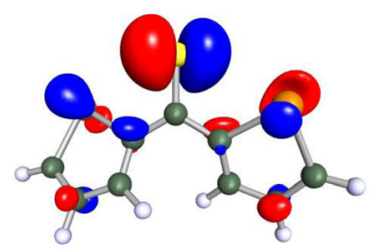

HOMO

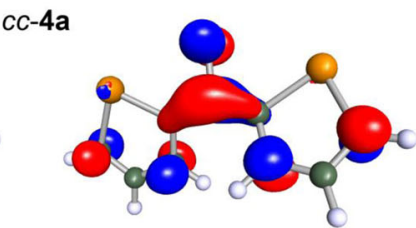

LUMO

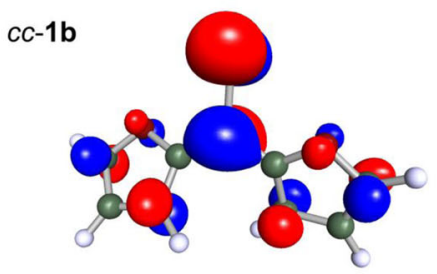

LUMO

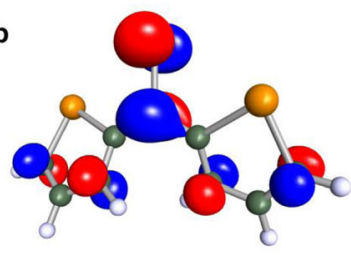

LUMO
Fig. 1 Frontier molecular orbitals of $\mathbf{1 a}, \mathbf{1 b}, \mathbf{4 a}$, and $\mathbf{4 b}$ adopting the $c c$ conformation. Contours of these orbitals are plotted with an isovalue of 0.05 a.u.
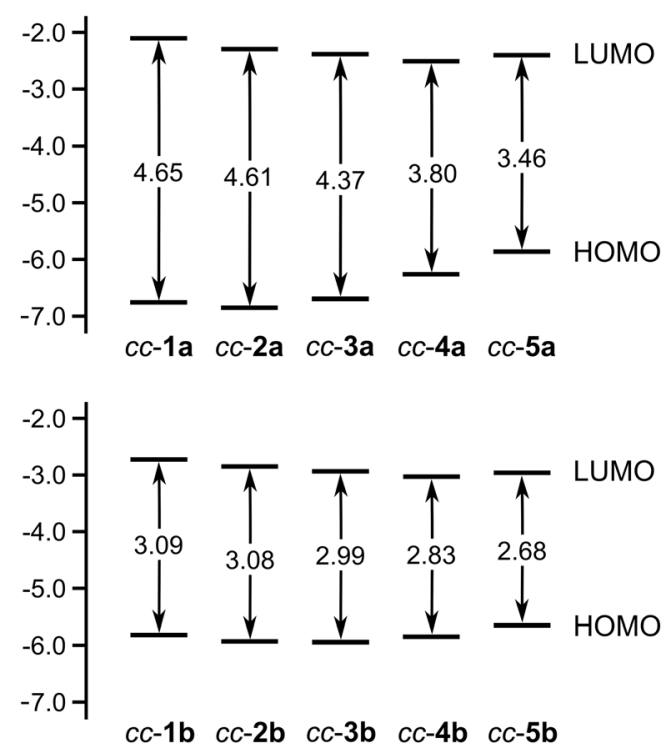

Fig. 2 Diagrams illustrating the highest occupied molecular orbital (HOMO) and the lowest unoccupied molecular orbital (LUMO) levels of the $c c$-conformers of $\mathbf{1 a - 5 a}$ and $\mathbf{1 b}-\mathbf{5 b}$ in vacuum. The energy gaps between these levels are also shown. All energies are given in $\mathrm{eV}$ 
also shown for each $c c$-conformer. It is apparent that the growing size of Y progressively narrows the HOMO-LUMO energy gap of both the ketones and thioketones adopting the $c c$ conformation. Such a finding is essentially valid for the other conformations of the investigated molecules (see Figs. S1 and $\mathrm{S} 2$ ). The impact of the kind of Y on the HOMO-LUMO energy gap of the $c c$-conformers of $\mathbf{1 a}-\mathbf{5 a}$ and $\mathbf{1} \mathbf{b}-\mathbf{5} \mathbf{b}$ mimics the corresponding heteroatom effect observed for a series of chalcophenes $\mathrm{C}_{4} \mathrm{H}_{4} \mathrm{Y}(\mathrm{Y}=\mathrm{O}, \mathrm{S}, \mathrm{Se}, \mathrm{Te})$ [50]. The narrowing of the HOMO-LUMO energy gap of $\mathbf{1 a - 5 a}$ and $\mathbf{1} \mathbf{b}-\mathbf{5 b}$ is the result of shifts in the HOMO and LUMO levels while replacing $\mathrm{Y}$ with the consecutive elements of group 16. According to the diagrams in Fig. 2, the HOMO level of the $c c$-conformers with heavy $\mathrm{Y}$ heteroatoms tends to lie higher in energy than the HOMO levels of the $c c$-conformers containing light $\mathrm{Y}$. The LUMO becomes in turn more and more stabilized, while moving down group 16 from $\mathrm{Y}=\mathrm{O}$ to $\mathrm{Y}=\mathrm{Te}$. These shifts in the HOMO and LUMO levels lead to a regular decrease in the values of the HOMO-LUMO energy gap as the $\mathrm{Y}$ heteroatom gets heavier. However, the planar geometry of $c t-1 \mathbf{a}, t t-\mathbf{1 a}$, and the nearly planar geometry of $c t-1 \mathbf{b}$ additionally stabilize the LUMO level of these conformers, yielding their HOMO-LUMO energy gaps smaller than those of $c t$ 2a, $t t-2 \mathbf{a}$, and $c t$-2b (see Figs. S1 and S2).

Changes in the HOMO-LUMO gap upon solvation are depicted in Fig. 3. In this figure, the polarity of the solvents is represented by the COSMO $\varepsilon$-dependent correction factor $f(\varepsilon)=(\varepsilon-1) /(\varepsilon+0.5)$ for dielectric screening energy [34]. It is evident from the figure that the changes in the HOMOLUMO energy gap of the $c c$-conformers are correlated with $f(\varepsilon)$; linear relationships between the HOMO-LUMO energy gap and $f(\varepsilon)$ are detected for the $c c$-conformers, but these relationships differ in the slope of regression line. For each $c c$-conformer, the relationship is established using four points corresponding to the HOMO-LUMO energy gaps of this $c c$ conformer in vacuum and three solvents.

A non-uniform behavior of $\mathbf{1 a}-\mathbf{5 a}$ versus $\mathbf{1 b}-\mathbf{5 b}$ can be seen while analyzing the solvent effect in Fig. 3. For the $c c$-conformers of the ketones, the presence of the solvents provokes a reduction in their HOMO-LUMO energy gap. Moreover, the HOMO-LUMO energy gap narrows gradually upon increasing the polarity of the solvents. This narrowing is predominantly caused by the stabilization of LUMO levels in the solvated $c c$ conformers (see Fig. S3). The HOMO levels are only marginally affected by solvation. The solvents usually have a slight destabilizing influence on these levels. Unlike the ketones, their thiocarbonyl analogs exhibit a broadening in their HOMO-LUMO energy gap upon solvation. The values of the HOMO-LUMO energy gap become larger when the solvent polarity increases. An exception to such a solvent effect occurs for $\mathbf{5 b}$, whose energy gap remains practically constant in vacuum and three solvents. The broadening of the HOMOLUMO energy gap of $\mathbf{1 b}-\mathbf{4 b}$ is mainly associated with their HOMO levels, which are shifted to lower (that is, more negative) energies upon solvation (see Fig. S4). The HOMO contours presented in Fig. 1 can serve as a rough rationalization for this shift. The HOMO of $c c$ $\mathbf{1 b}$ and $c c-\mathbf{4 b}$ resides mainly on the thiocarbonyl $\mathrm{S}$ atom, and the resulting polarization of the HOMO toward the $\mathrm{S}$ atom suggests a greater stabilization by more polar solvents. In the case of the LUMO levels of $\mathbf{1 b}-\mathbf{5 b}$, their stabilization is triggered by the solvents. Unsurprising, this effect is common to both the ketones and thioketones, which is due to the striking similarity of their LUMOs. The aforementioned trends in the solvent effects on the HOMO-LUMO energy gap of the
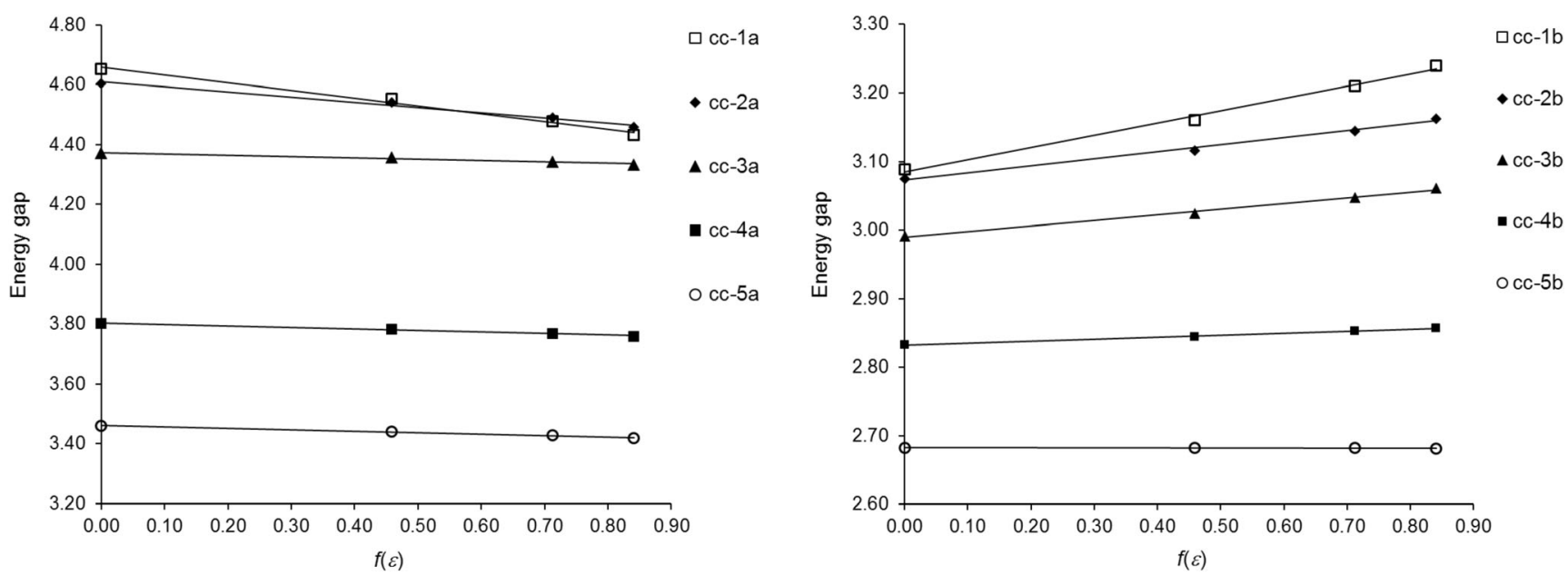

Fig. 3 Plots of the HOMO-LUMO energy gap (in eV) against the COSMO correction factor $f(\varepsilon)$ for the $c c$-conformers of $\mathbf{1 a}-\mathbf{5} \mathbf{a}$ and $\mathbf{1 b}-\mathbf{5 b}$ in vacuum and three solvents. The $f(\varepsilon)$ values of vacuum, benzene, chloroform, and dichloromethane amount to $0.00,0.46,0.71$, and 0.84 , respectively 
$c c$-conformers of $\mathbf{1 a - 5 a}$ and $\mathbf{1 b}-\mathbf{5 b}$ are also valid for the $c t$ - and $t$-conformers of these compounds.

\section{Dipole moment}

The molecular dipole moment, $\mu$, is an essential quantity describing the spatial distribution of electron charge within a molecule. It is known that the magnitude and direction of $\mu$ is sensitive to molecular size and shape, and, in consequence, different conformers of a molecule can have very different dipole moments. This happens to the molecules of $\mathbf{1 a}-\mathbf{5 a}$ and $\mathbf{1 b}-\mathbf{5 b}$, which can adopt three conformations, each exhibiting its own abundance at $298.15 \mathrm{~K}$. Therefore, it is reasonable to characterize the dipole moment of every single compound of interest by using its conformationally weighted dipole moment $\mu_{\mathrm{cw}}$ (a methodology for calculating $\mu_{\mathrm{cw}}$ is proposed in section S1). The calculated values of $\mu_{\mathrm{cw}}$ for $\mathbf{1 a}-\mathbf{5 a}$ and $\mathbf{1 b}-\mathbf{5 b}$ are shown in Table 3.

We begin by discussing the calculated $\mu_{\mathrm{cw}}$ values for the molecules of $\mathbf{1 a}-\mathbf{5 a}$ and $\mathbf{1 b}-\mathbf{5 b}$ in vacuum. The $\mu_{\mathrm{cw}}$ values of the ketones range between $1.98 \mathrm{D}$ and 3.72 D. The effect of the type of ring heteroatom on these values is clearly evident; there is a gradual decrease in $\mu_{\mathrm{cw}}$ while Y descends through group 16. The same effect occurs for the thioketones. Their range of $\mu_{\mathrm{cw}}$ is shifted toward higher values, but it is still of similar width to that found for the ketones. The effect of $\mathrm{Y}$ on $\mu_{\mathrm{cw}}$ can be rationalized in terms of variations in the electronegativity of $\mathrm{Y}$, and in the resultant local dipole moment of a heteroaryl substituent. The decrease of $\mathrm{Y}$ electronegativity along the series from $\mathrm{Y}=\mathrm{O}$ to $\mathrm{Y}=\mathrm{Te}$ is associated with a decrease in the local dipole moment of the corresponding heteroaryl substituent. The local dipole moment of a heteroaryl ring with $\mathrm{Y}=\mathrm{O}-\mathrm{Se}$ acts from the $\mathrm{Y}$ heteroatom toward the ring center (assuming that the dipole vector is directed toward the center of positive partial charge). Two such oriented dipole moments added to the local dipole vector of the $\mathrm{C}=\mathrm{X}$ group generate a large molecular dipole moment for the $c c$ conformers of $\mathbf{1 a}-\mathbf{3 a}$ and $\mathbf{1 b}-\mathbf{3 b}$. Our calculations of $\mu$ for tellurophene predict a negligible value of $0.04 \mathrm{D}$, while polonophene possesses larger $\mu(0.44 \mathrm{D})$ yet its orientation is reversed. The local dipole moments of the polonophen-2-yl rings compensate to a certain degree the local dipole moment of the $\mathrm{C}=\mathrm{X}$ group for the $c c$-conformers of $\mathbf{5} \mathbf{a}$ and $\mathbf{5 b}$. The high abundance of these conformers has, in turn, a direct effect on $\mu_{\mathrm{cw}}$, and, therefore, the values of $\mu_{\mathrm{cw}}$ for $\mathbf{5 a}$ and $\mathbf{5 b}$ are smallest in both series of compounds.

The comparison of $\mu_{\mathrm{cw}}$ for every $\mathbf{1 a}-\mathbf{5 a}$ in vacuum with $\mu_{\mathrm{cw}}$ for the corresponding thiocarbonyl analog reveals that the former is generally smaller in magnitude than the latter. This indicates that the distribution of electron charge is less polarized within the molecules of the ketones than within the molecules of the corresponding thioketones. The $\mu_{\mathrm{cw}}$ values of $\mathbf{1 a}-\mathbf{5} \mathbf{a}$ turn out to be smaller despite the fact that the electronegativity of oxygen is larger than that of sulfur and, in principle, the $\mathrm{C}=\mathrm{O}$ group as such is more polarized than the $\mathrm{C}=\mathrm{S}$ group [51]. In this case, the electron donor-acceptor properties of heteroaryl rings become a factor reinforcing the charge separation within the molecules of $\mathbf{1 b}-\mathbf{5 b}$. An increase in the magnitude of molecular dipole moment upon replacing $\mathrm{C}=\mathrm{O}$ by $\mathrm{C}=\mathrm{S}$ was previously observed for diaryl ketones [52] and for uracil and its thio-analogs [53].

Having analyzed the $\mu_{\mathrm{cw}}$ values in vacuum, we turn our attention to the solvent effect on $\mu_{\mathrm{cw}}$. It is evident from Table 3 that the $\mu_{\mathrm{cw}}$ values of the investigated compounds in three solvents are always larger than those characterizing these compounds in vacuum. This indicates a stronger charge separation within the solvated molecules of $\mathbf{1 a}-\mathbf{5 a}$ and $\mathbf{1 b}-\mathbf{5 b}$ than within the corresponding isolated molecules. This is because the charge distribution of each solute molecule polarizes the solvent, which, in turn, acts back on the solute molecule, enhancing its intramolecular

Table 3 Conformationally weighted dipole moments ( $\mu_{\mathrm{cw}}$ in Debye), polarizabilities $\left(\alpha_{\mathrm{cw}}\right.$ in $\left.\AA^{3}\right)$ and polarizability anisotropies $\left(\Delta \alpha_{\mathrm{cw}}\right.$ in $\left.\AA^{3}\right)$ for $\mathbf{1 a}-$ $\mathbf{5 a}$ and $\mathbf{1 b}-\mathbf{5 b}$ in vacuum and solvents

\begin{tabular}{|c|c|c|c|c|c|c|c|c|c|c|c|c|}
\hline \multirow[t]{3}{*}{ Compound } & \multicolumn{12}{|c|}{ Medium } \\
\hline & \multicolumn{3}{|c|}{ Vacuum } & \multicolumn{3}{|c|}{ Benzene } & \multicolumn{3}{|c|}{ Chloroform } & \multicolumn{3}{|c|}{ Dichloromethane } \\
\hline & $\mu_{\mathrm{cw}}$ & $\alpha_{\mathrm{cw}}$ & $\Delta \alpha_{\mathrm{cw}}$ & $\mu_{\mathrm{cw}}$ & $\alpha_{\mathrm{cw}}$ & $\Delta \alpha_{\mathrm{cw}}$ & $\mu_{\mathrm{cw}}$ & $\alpha_{\mathrm{cw}}$ & $\Delta \alpha_{\mathrm{cw}}$ & $\mu_{\mathrm{cw}}$ & $\alpha_{\mathrm{cw}}$ & $\Delta \alpha_{\mathrm{cw}}$ \\
\hline 1a & 3.72 & 18.2 & 14.5 & 3.81 & 21.2 & 16.7 & 3.84 & 23.5 & 18.4 & 3.87 & 24.9 & 19.5 \\
\hline $2 a$ & 3.60 & 22.4 & 15.8 & 3.64 & 26.5 & 17.9 & 3.68 & 29.5 & 19.5 & 3.71 & 31.4 & 20.5 \\
\hline $3 a$ & 3.50 & 24.7 & 16.8 & 3.51 & 29.3 & 19.0 & 3.51 & 32.9 & 20.6 & 3.52 & 35.0 & 21.6 \\
\hline $4 a$ & 2.78 & 29.1 & 18.9 & 2.79 & 34.8 & 21.3 & 2.79 & 39.2 & 23.0 & 2.79 & 42.0 & 24.0 \\
\hline $5 a$ & 1.98 & 31.5 & 20.0 & 1.99 & 38.2 & 22.4 & 2.01 & 43.4 & 24.0 & 2.02 & 46.7 & 25.0 \\
\hline $1 \mathrm{~b}$ & 4.03 & 22.7 & 17.2 & 4.04 & 27.3 & 20.7 & 4.08 & 30.9 & 23.6 & 4.11 & 33.2 & 25.5 \\
\hline $2 \mathrm{~b}$ & 3.86 & 26.7 & 17.9 & 3.88 & 32.2 & 21.4 & 3.90 & 36.5 & 24.2 & 3.91 & 39.3 & 26.1 \\
\hline $3 b$ & 3.69 & 29.0 & 19.4 & 3.69 & 35.2 & 23.1 & 3.69 & 40.1 & 26.1 & 3.70 & 43.2 & 28.1 \\
\hline $4 b$ & 3.02 & 33.4 & 22.9 & 3.03 & 40.8 & 27.0 & 3.03 & 46.7 & 30.2 & 3.03 & 50.5 & 32.3 \\
\hline $5 b$ & 2.34 & 35.9 & 24.4 & 2.35 & 44.3 & 28.7 & 2.37 & 51.1 & 32.0 & 2.39 & 55.5 & 34.1 \\
\hline
\end{tabular}


charge separation and magnitude of molecular dipole moment. As states above, $\mu_{\mathrm{cw}}$ grows if the phase of each compound has been altered from vacuum to solution, and additionally, the resulting growth of $\mu_{\mathrm{cw}}$ is enhanced by the increasing polarity of the solvents. Thus, the largest $\mu_{\mathrm{cw}}$ values are observed for the investigated compounds solvated by dichloromethane. The growth of $\mu_{\mathrm{cw}}$ is, however, rather minor and does not exceed several percent, compared to $\mu_{\mathrm{cw}}$ in vacuum (the maximal $\mu_{\mathrm{cw}}$ growth amounting to $4.1 \%$ is observed for $\mathbf{1 a}$ in dichloromethane). This also suggests that there will be a modest increase in the intermolecular solute-solvent interaction if the solvent is changed from benzene to dichloromethane.

There are available experimental values of molecular dipole moment for three out of ten investigated compounds. Experimental measurements were made for 1a (3.65 D), 2a (3.71 D), and 2b (3.75 D), all in benzene solution [54]. The $\mu_{\mathrm{cw}}$ values calculated for $\mathbf{1 a}, \mathbf{1 b}$, and $\mathbf{2 b}$ in benzene reproduce the corresponding experimental dipole moments with an accuracy of $0.16 \mathrm{D}$ or better. The agreement of the trend in the $\mu_{\mathrm{cw}}$ values with the experimental results was, however, successful only in part. The $\mu_{\mathrm{cw}}$ values of $\mathbf{2} \mathbf{a}$ and $\mathbf{2} \mathbf{b}$ mimic the experimentally measured growth of molecular dipole moment. The $\mu_{\mathrm{cw}}$ values of $\mathbf{1 a}$ and $\mathbf{2 a}$, by contrast, do not follow the experimental trend. One should bear in mind that both the experimental dipole moments and $\mu_{\mathrm{cw}}$ characterize the equilibrium mixtures of conformers, so the aforementioned disagreement may result even from a minor difference in the abundance of individual conformers.

Next, the analysis of the molecular dipole moments of $\mathbf{1 a}-\mathbf{5 a}$ and $\mathbf{1 b}-\mathbf{5 b}$ will be deepened by inspecting the $\mu$ values of individual conformers. The $\mu$ values of all investigated conformers are collected in Table 4. It is apparent that there are noticeable differences in $\mu$ between individual conformers of every compound. For 1a-3a and their thiocarbonyl counterparts, the $c c$ conformation exhibits the largest values of $\mu$, whereas the $t t$ conformers possess the smallest $\mu$ values. The molecular dipole moments of $\mathbf{4 a}, \mathbf{4 b}, \mathbf{5} \mathbf{a}$, and $\mathbf{5 b}$ are also sensitive to conformational changes, but these compounds show an increase in their $\mu$ values while passing from the $c c$-conformation to the $c t$-conformation and further to the $t t$-conformation. For all conformers, the spatial orientation of their $\mu$ vectors is determined, to a great extent, by the orientation of the local dipole moment of their $\mathrm{C}=\mathrm{O}$ or $\mathrm{C}=\mathrm{S}$ group (this local dipole moment is directed from the $\mathrm{O}$ or $\mathrm{S}$ atom toward the $\mathrm{C}$ atom). The relation between the increment of $\mu$ and the kind of conformation can be understood in terms of the local dipole moments ascribed to the heteroaryl fragments and the $\mathrm{C}=\mathrm{O}$ and $\mathrm{C}=\mathrm{S}$ groups. The orientations of these local dipole moments for the $c c$-conformers of $\mathbf{1 a}-\mathbf{5 a}$ and $\mathbf{1 b}-\mathbf{5 b}$ have been discussed earlier in this subsection. The $t t$ conformers of $\mathbf{1 a}-\mathbf{3} \mathbf{a}$ and $\mathbf{1 b}-\mathbf{3 b}$ possess the smallest $\mu$ values because the local dipole moments of their heteroaryl fragments and of their $\mathrm{C}=\mathrm{O}$ and $\mathrm{C}=\mathrm{S}$ groups are directed oppositely. These local dipole moments demonstrate an approximately
Table 4 Dipole moments ( $\mu$ in Debye) for the conformers of 1a-5a and $\mathbf{1 b}-\mathbf{5 b}$ in vacuum and solvents

\begin{tabular}{|c|c|c|c|}
\hline Conformer & $\mu^{\mathrm{a}}$ & Conformer & $\mu^{\mathrm{a}}$ \\
\hline$c c-1 \mathbf{a}$ & $4.75 / 5.67 / 6.38 / 6.82$ & $c c-\mathbf{1 b}$ & $4.72 / 5.86 / 6.79 / 7.39$ \\
\hline$c t-\mathbf{1 a}$ & $3.91 / 4.69 / 5.27 / 5.64$ & $c t-\mathbf{1 b}$ & $4.10 / 5.10 / 5.92 / 6.44$ \\
\hline$t t-\mathbf{1 a}$ & $2.90 / 3.45 / 3.87 / 4.12$ & $t t-\mathbf{1 b}$ & $3.35 / 4.14 / 4.77 / 5.19$ \\
\hline$c c-\mathbf{2 a}$ & $4.03 / 4.89 / 5.55 / 5.97$ & $c c-\mathbf{2 b}$ & $4.14 / 5.17 / 6.02 / 6.57$ \\
\hline$c t-\mathbf{2 a}$ & $3.36 / 4.09 / 4.66 / 5.01$ & $c t-\mathbf{2 b}$ & $3.62 / 4.52 / 5.26 / 5.74$ \\
\hline$t t-2 \mathbf{a}$ & $2.69 / 3.27 / 3.72 / 4.00$ & $t t-\mathbf{2} \mathbf{b}$ & $3.09 / 3.84 / 4.45 / 4.85$ \\
\hline$c c-\mathbf{3 a}$ & $3.65 / 4.47 / 5.11 / 5.52$ & $c c-\mathbf{3 b}$ & $3.81 / 4.79 / 5.60 / 6.13$ \\
\hline$c t-\mathbf{3 a}$ & $3.20 / 3.93 / 4.50 / 4.87$ & $c t-\mathbf{3 b}$ & $3.46 / 4.36 / 5.10 / 5.59$ \\
\hline$t t-\mathbf{3 a}$ & $2.80 / 3.44 / 3.94 / 4.26$ & $t t-\mathbf{3 b}$ & $3.17 / 3.98 / 4.64 / 5.08$ \\
\hline$c c-\mathbf{4 a}$ & $2.76 / 3.42 / 3.96 / 4.30$ & $c c-\mathbf{4 b}$ & $3.00 / 3.83 / 4.52 / 4.98$ \\
\hline$c t-\mathbf{4 a}$ & $2.94 / 3.67 / 4.26 / 4.63$ & $c t-\mathbf{4 b}$ & $3.19 / 4.08 / 4.83 / 5.33$ \\
\hline$t t-\mathbf{4 a}$ & $3.24 / 4.02 / 4.63 / 5.03$ & $t t-4 \mathbf{b}$ & $3.60 / 4.58 / 5.40 / 5.94$ \\
\hline$c c-\mathbf{5 a}$ & $1.93 / 2.32 / 2.66 / 2.89$ & $c c-\mathbf{5 b}$ & $2.28 / 2.87 / 3.39 / 3.74$ \\
\hline$c t-\mathbf{5 a}$ & $2.85 / 3.62 / 4.26 / 4.68$ & $c t-5 \mathbf{b}$ & $3.10 / 4.06 / 4.90 / 5.47$ \\
\hline$t t-5 \mathbf{a}$ & $3.82 / 4.89 / 5.77 / 6.35$ & $t t-5 \mathbf{b}$ & $4.17 / 5.50 / 6.64 / 7.43$ \\
\hline
\end{tabular}

${ }^{\mathrm{a}}$ The $\mu$ values are listed in the following media: vacuum/benzene/chloroform/dichloromethane

concordant direction for the $t t$-conformers of $\mathbf{5} \mathbf{a}$ and $\mathbf{5 b}$, and, therefore, their $t t$-conformation exhibits the largest $\mu$ values.

The effect on $\mu$ exerted by the solvents is not of identical magnitude for all conformers. For each compound, the difference between the $\mu$ values of its most polar and least polar conformers increases upon solvation, and such a difference keeps growing with increasing solvent polarity. The conformers of $\mathbf{1 b}-\mathbf{5 b}$ exhibit higher growth of $\mu$ upon solvation than the corresponding ketone conformers. This is in agreement with previous findings reported for formaldehyde and thioformaldehyde solvated in water [55]. The polarity of the $\mathrm{C}-\mathrm{S} \pi$ bond in thioformaldehyde is increased to a greater extent than that observed for the $\mathrm{C}-\mathrm{O} \pi$ bond in formaldehyde.

Finally, it is instructive to relate the abundances of solvated conformers in their equilibrium mixtures to the changes of their $\mu$ values upon solvation. In principle, it can be expected that a conformer possessing a high $\mu$ value becomes more favorable in solvents of high polarity [56]. Such a relationship exists for the solvated conformers of $\mathbf{1 a}-\mathbf{5 a}$ and $\mathbf{1 b}-\mathbf{5 b}$, and their percentage abundances shown in Tables 1 and 2 provide evidence confirming this. Among the three conformations of 1a-3a and 1b-3b in vacuum, the $c c$-conformers exhibit the highest $\mu$ values; hence, these conformers become more and more abundant in the solvents of increasing polarity. The same concerns the $t t$-conformers of $\mathbf{4 a}, \mathbf{4 b}, \mathbf{5 a}$, and $\mathbf{5 b}$, although these conformers are still much higher in energy than the preferred conformers, and, therefore, the abundances of the $t t$-conformers rise extremely slowly (their tabulated percentage abundances sometimes seem not to grow, but this is because the percentage abundances have been rounded to one digit after the decimal point). 


\section{Polarizability}

The molecular average dipole polarizability $\alpha$ and the polarizability anisotropy $\Delta \alpha$ measure the deformation of charge distribution within a molecule under an applied external electric field. Here, the importance of $\alpha$ and $\Delta \alpha$ is attributed to the fact that these quantities may be good indicators of how the deformation of charge distribution within the investigated molecules is affected by the kind of Y and the presence of solvent. Similarly to $\mu_{\mathrm{cw}}$, the $\alpha$ and $\Delta \alpha$ values of three conformers of each compound are subjected to conformational weighting in order to obtain $\alpha_{\mathrm{cw}}$ and $\Delta \alpha_{\mathrm{cw}}$. The $\alpha_{\mathrm{cw}}$ and $\Delta \alpha_{\mathrm{cw}}$ values calculated for $\mathbf{1 a}-\mathbf{5 a}$ and $\mathbf{1 b}-$ $\mathbf{5 b}$ are appended to Table 3 .

The Y heteroatom effect on $\alpha_{\mathrm{cw}}$ and $\Delta \alpha_{\mathrm{cw}}$ is the opposite of that detected for $\mu_{\mathrm{cw}}$. For each series of compounds, the replacement of oxygen by a heavier group 16 element at the $Y$ position increases the values of $\alpha_{\mathrm{cw}}$ and $\Delta \alpha_{\mathrm{cw}}$ gradually. The distribution of electron charge in $\mathbf{5} \mathbf{a}$ and $\mathbf{5 b}$ undergoes the greatest distortion caused by an external electric field. The trend in $\alpha_{\mathrm{cw}}$ can be interpreted in terms of changes in the molecular polarizabilities of five-membered heterocycles $\mathrm{C}_{4} \mathrm{H}_{4} \mathrm{Y}$. Figure 4 proves that the $\alpha_{\mathrm{cw}}$ values of $\mathbf{1 a}-\mathbf{5 a}$ in vacuum are linearly correlated with the polarizabilities of isolated chalcophenes. The same applies to the thioketones. The $\alpha_{\mathrm{cw}}$ values of $\mathbf{1 b}-\mathbf{5 b}$ are shifted toward more positive values due to the higher atomic polarizability of the thiocarbonyl $\mathrm{S}$ atom compared to the $\mathrm{O}$ atom of the $\mathrm{C}=\mathrm{O}$ group. The molecular polarizabilities of $\mathrm{C}_{4} \mathrm{H}_{4} \mathrm{Y}$ heterocycles are, in turn, in excellent linear correlation with the atomic polarizabilities of the corresponding $\mathrm{Y}$ atoms [57]. This indicates that the evolution of $\alpha_{\text {cw }}$ along the series of the ketones or thioketones investigated here is determined mainly by the kind of Y heteroatom.

The heteroatom effect on polarizability can also be rationalized in terms of HOMO-LUMO energy gap and molecular size

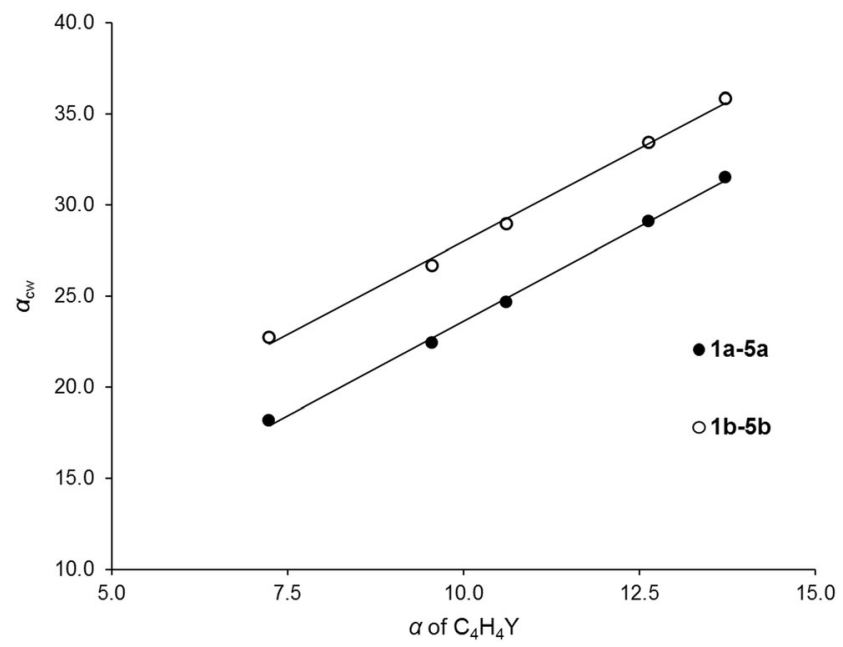

Fig. 4 Plot of the conformationally weighted polarizability of 1a-5a and $\mathbf{1 b}-\mathbf{5 b}$ in vacuum $\left(\alpha_{\mathrm{cw}}\right.$ in $\left.\AA^{3}\right)$ against the polarizability of parent heterocyclic molecules $\mathrm{C}_{4} \mathrm{H}_{4} \mathrm{Y}$ in vacuum $\left(\alpha\right.$ in $\left.\AA^{3}\right)$ for a fixed type of molecular conformation. In principle, the polarizability of a molecule is expected to be enhanced with the decreasing HOMO-LUMO energy gap and growing size of the molecule [58]. As noted earlier in this work, replacing $\mathrm{Y}$ with a heavier and heavier group 16 element leads to reduction of the HOMO-LUMO energy gap. This reduction is indeed inversely related with $\alpha$ for the isolated $c c$-conformers of $\mathbf{1 a}-\mathbf{5 a}$ and $\mathbf{1 b}-\mathbf{5 b}$ (see Fig. S5). Additionally, there is an approximately linear relationship between $\alpha$ and the molecular volume of the isolated $c c$-conformers of the investigated compounds (Fig. S5). This reflects the well-known proportionality between molecular polarizability and molecular size [58]. The use of the molecular volume of the $c c$-conformers to estimate their molecular size turns out to be successful for providing a clear correlation with $\alpha$. On the one hand, this may be a consequence of the structural similarity of the $c c$-conformers. On the other hand, the existence of a general relationship between polarizability and volume was previously postulated, although such a relationship did not fulfill an ideal linear correlation [59].

The $\alpha_{\mathrm{cw}}$ and $\Delta \alpha_{\mathrm{cw}}$ values of $\mathbf{1 a}-\mathbf{5 a}$ and $\mathbf{1 b}-\mathbf{5 b}$ in three solvents are reported in Table 3. An inspection of these values reveals that they are affected by the presence and kind of solvents. Compared to $\alpha_{\mathrm{cw}}$ and $\Delta \alpha_{\mathrm{cw}}$ of $\mathbf{1 a}-\mathbf{5 a}$ and $\mathbf{1 b}-\mathbf{5 b}$ in vacuum, the $\alpha_{\mathrm{cw}}$ and $\Delta \alpha_{\mathrm{cw}}$ values of solvated molecules are noticeably larger, and they increase further with the growing polarity of solvents. The growth of $\alpha_{\mathrm{cw}}$ and $\Delta \alpha_{\mathrm{cw}}$ for the molecules solvated in dichloromethane can reach even $50 \%$ of the $\alpha_{\mathrm{cw}}$ and $\Delta \alpha_{\mathrm{cw}}$ values for the corresponding isolated molecules. The growing solvent polarity facilitates the charge separation within the molecules of $\mathbf{1 a}-\mathbf{5 a}$ and $\mathbf{1 b}-\mathbf{5 b}$, which, in turn, enhances the deformation of their charge distribution under an external electric field. For $\mathbf{1 a}-\mathbf{5 a}$, the solvent effect may also be explained by the continuous decrease of the HOMO-LUMO energy gap (see Fig. 2). Such an explanation does not apply to the thioketones, for which the growth of their molecular volume upon solvation determines the increase of $\alpha$ (for details, consult Figs. S6 and S7).

The molecular polarizability is only very slightly sensitive to the conformation adopted by the molecules of $\mathbf{1 a - 5 a}$ and 1b-5b. Therefore, the $\alpha$ values of three conformers of each compound show much lower variability than the $\mu$ values. From an experimental perspective, the $\alpha$ values seem of little use to unambiguously distinguish the conformers from each other.

\section{Summary}

Density functional theory calculations of geometry, energetics, frontier molecular orbitals, dipole moment and polarizability for formaldehyde and thioformaldehyde symmetrically disubstituted with five-membered heteroaromatic rings containing a single group 16 heteroatom have yielded a detailed picture of variations in these molecular properties as a result of 
replacing the ring heteroatom (i.e., oxygen) by a heavier element, up to polonium. Furthermore, embedding the molecules of the investigated compounds in a continuum with a small dielectric constant of benzene, chloroform, or dichloromethane has served as a computational tool for establishing to what extent the presence of these low polarity solvents affects the aforementioned properties.

The effect of ring heteroatom on the preferred geometrical orientation of heteroaryl rings is non-uniform for $\mathbf{1 a}-\mathbf{5 a}$ and $\mathbf{1 b}-\mathbf{5 b}$. The furan-2-yl substituents of $\mathbf{1 a}$ and $\mathbf{1 b}$ favor the $c t$ conformation, whereas the heavier $Y$ heteroatoms tend to prefer the $c c$-conformation. The presence of a solvent further diversifies the conformational behavior of the investigated molecules. The three solvents stabilize the $c c$-conformation of the heteroaryl rings containing $\mathrm{Y}=\mathrm{O}-\mathrm{Se}$ and destabilize this conformation if $\mathrm{Y}=\mathrm{Te}$, Po. Such a solvent effect may be rationalized by the analysis of molecular dipole moment for individual conformers. Even if the solvents display low polarity, they have a noticeable influence on the percentage abundances of three conformers in their equilibrium mixture at $298.15 \mathrm{~K}$. The HOMO-LUMO energy gap of $\mathbf{1 a - 5 a}$ and $\mathbf{1 b}-\mathbf{5 b}$ gradually decreases while $\mathrm{Y}$ descends through group 16. Two opposite trends in this property are detected for the solvated molecules $(\mathbf{1} \mathbf{a}-\mathbf{5 a}$ versus $\mathbf{1 b}-\mathbf{5 b})$, which is attributed to different stabilization/destabilization patterns of frontier molecular orbitals in the two series of molecules. The growing size of $Y$ is associated with the decrease of $\mu_{\mathrm{cw}}$ and, simultaneously, with the increases of $\alpha_{\mathrm{cw}}$ and $\Delta \alpha_{\mathrm{cw}}$. These changes correlate with the electronegativity and polarizability of Y. Both $\mu_{\mathrm{cw}}$ and $\alpha_{\mathrm{cw}}$ increase when the solvents have been introduced. However, $\alpha_{\mathrm{cw}}$ is much more sensitive to the growing polarity of the solvents than is $\mu_{\mathrm{cw}}$.

We believe that this work may contribute to a better understanding of the role of heteroatom and solvent in establishing structure-property patterns for organic molecules containing $\mathrm{C}_{4} \mathrm{H}_{3} \mathrm{Y}$ groups.

Acknowledgement This work was partially supported by PL-Grid Infrastructure.

Open Access This article is distributed under the terms of the Creative Commons Attribution 4.0 International License (http:// creativecommons.org/licenses/by/4.0/), which permits unrestricted use, distribution, and reproduction in any medium, provided you give appropriate credit to the original author(s) and the source, provide a link to the Creative Commons license, and indicate if changes were made.

\section{References}

1. Joule JA, Mills K (2010) Heterocyclic chemistry, 5th edn. Wiley, Chichester

2. Nylund K, Johansson P, Puterova Z, Krutosikova A (2010) Heterocyclic compounds: synthesis, properties and applications. Nova Science, Hauppauge
3. Quin LD, Tyrell J (2010) Fundamentals of heterocyclic chemistry: importance in nature and in the synthesis of pharmaceuticals. Wiley, Hoboken

4. Balaban AT, Oniciu DC, Katritzky AR (2004) Aromaticity as a cornerstone of heterocyclic chemistry. Chem Rev 104:2777-2812

5. Belen'kii LI, Suslov IA, Chuvylkin ND (2003) Substrate and positional selectivity in electrophilic substitution reactions of pyrrole, furan, thiophene, and selenophene derivatives. Chem Heterocycl Compd 39:36-48

6. Ortiz P, del Hoyo AM, Harutyunyan SR (2015) Catalytic asymmetric alkylation of aryl heteroaryl ketones. Eur J Org Chem 2015:72-76

7. Mlostoń G, Grzelak P, Mikina M, Linden A, Heimgartner H (2015) Hetero-Diels-Alder reactions of hetaryl and aryl thioketones with acetylenic dienophiles. Beilstein J Org Chem 11:576-582

8. Zhang G, Ma J, Wen J (2007) Interchain impacts on electronic structures of heterocyclic oligomers and polymers containing group 14,15 , and 16 heteroatoms: quantum chemical calculations in combination with molecular dynamics simulations. J Phys Chem B 111: 11670-11679

9. Zajac M, Hrobarik P, Magdolen P, Foltınova P, Zahradnık P (2008) Donor- $\pi$-acceptor benzothiazole-derived dyes with an extended heteroaryl-containing conjugated system: synthesis, DFT study and antimicrobial activity. Tetrahedron 64:10605-10618

10. Acharya R, Cekli S, Zeman CJ, Altamimi RM, Schanze KS (2016) Effect of selenium substitution on intersystem crossing in $\pi$ conjugated donor-acceptor-donor chromophores: the LUMO matters the most. J Phys Chem Lett. 7:693-697

11. Kobilka BM, Hale BJ, Ewan MD, Dubrovskiy AV, Nelson TL, Duzhkoc V, Jeffries-EL M (2013) Influence of heteroatoms on photovoltaic performance of donor-acceptor copolymers based on 2,6di(thiophen-2-yl)benzo[1,2-b:4,5-b']difurans and diketopyrrolopyrrole. Polym Chem 4:5329-5336

12. Raychev D, Guskova O, Seifert G, Sommer J-U (2017) Conformational and electronic properties of small benzothiadiazole-cored oligomers with aryl flanking units: thiophene versus furan. Comput Mater Sci 126:287-298

13. Sperry JB, Wright DL (2005) Furans, thiophenes and related heterocycles in drug discovery. Curr Opin Drug Discov Devel 8:723-740

14. Pitucha M, Pachuta-Stec A, Kaczor AA (2013) New fivemembered ring heterocyclic compounds with antibacterial and antifungal activity. In: Méndez-Vilas A (ed) Microbial pathogens and strategies for combating them: science, technology and education, vol 1. Microbiology Book Series \#4. Formatex Research Center, Badajoz, pp 562-573

15. Ruengsangtongkul S, Taprasert P, Sirion U, Jaratjaroonphong J (2016) Facile synthesis of nonsymmetrical heteroarylsubstituted triarylmethanes via the $\mathrm{FeCl}_{3} \cdot 6 \mathrm{H}_{2} \mathrm{O}$-catalyzed two-step Friedelcrafts-type reaction. Org Biomol Chem 14:8493-8502

16. Guerra M, Pedulli GF, Tiecco M, Martelli G (1974) Conformational isomers and rotational barriers in the ketyl radicals of thiophen and thienothiophens. J Chem Soc Perkin Trans 2 1974:562-567

17. Benassi R, Folli U, Iarossi D, Schenetti L, Taddei F, Musatti A, Nardelli M (1989) Conformational analysis of organic carbonyl compounds. Part 11. Conformational properties of difuryl, dithienyl, and furyl thienyl ketones studied by X-ray crystallography, N.M.R. lanthanide-induced shifts and ab-initio MO calculations. J Chem Soc Perkin Trans 2 1989:1741-1751

18. Rhyman L, Abdallah HH, Ramasami P (2011) Quantum mechanical study of the syn-anti isomerisation of 2-tellurophenecarboaldehyde: vive la différence. Spectrochim Acta A 78:258-263

19. Taylor R (1968) Measurement of electrophilic aromatic reactivities via pyrolysis of 1-arylethyl acetates. Part 11. The 2- and 3-positions of furan and thiophen. J Chem Soc B 1968:1397-1401

20. Becker RS, Favaro G, Poggi G, Romani A (1995) Photophysical properties of some thienyl ketones: an experimental and theoretical study. J Phys Chem 99:1410-1417 
21. Wang H, Wang L, Shen S, Zhang W, Li M, Du L, Zheng X, Phillips DL (2012) Effects of hydrogen bond and solvent polarity on the $\mathrm{C}=\mathrm{O}$ stretching of bis(2-thienyl)ketone in solution. J Chem Phys 136:124509/1-11

22. Mlostoń G, Pipiak P, Linden A, Heimgartner H (2015) Studies on the reactions of thiocarbonyl S-methanides with hetaryl thioketones. Helv Chim Acta 98:462-473

23. Mlostoń G, Pipiak P, Heimgartner H (2016) Diradical reaction mechanisms in $[3+2]$-cycloadditions of hetaryl thioketones with alkyl- or trimethylsilyl-substituted diazomethanes. Beilstein J Org Chem 12:716-724

24. Mlostoń G, Urbaniak K, Gębicki K, Grzelak P, Heimgartner H (2014) Hetaryl thioketones: synthesis and selected reactions. Heteroat Chem 25:548-555

25. da Silva Miranda F, Gava Menezes F, Vicente J, Bortoluzzi AJ, Zucco C, Neves A, Sanches Gonçalves N (2009) Bis- $(1 \mathrm{H}-$ benzimidazol-2-yl)-methanone: new preparation method, crystal structure, vibrational spectroscopy and DFT calculations. J Mol Struct 938:1-9

26. Matczak P, Domagała M, Domagała S (2016) Conformers of diheteroaryl ketones and thioketones: a quantum chemical study of their properties and fundamental intramolecular energetic effects. Struct Chem 27:855-869

27. Dal Colle M, Cova C, Distefano G, Jones D, Modelli A, Comisso N (1999) Determination of the electronic structure of oligo(2-thienyl ketones) and extrapolation to poly(thienylene ketone). J Phys Chem A 103:2828-2835

28. Matczak P (2016) Intramolecular $\mathrm{C}-\mathrm{H} \cdots \mathrm{H}-\mathrm{C}$ contacts in diheteroaryl ketones and thioketones: a theoretical analysis. Bull Chem Soc Jpn 89:92-102

29. Becke AD (1993) Density-functional thermochemistry. III. The role of exact exchange. J Chem Phys 98:5648-5642

30. Vosko SH, Wilk L, Nusair M (1980) Accurate spin-dependent electron liquid correlation energies for local spin density calculations: a critical analysis. Can J Phys 58:1200-1211

31. Lee C, Yang W, Parr RG (1988) Development of the Colle-Salvetti correlation-energy formula into a functional of the electron density. Phys Rev B 37:785-789

32. Weigend F, Ahlrichs R (2005) Balanced basis sets of split valence, triple zeta valence and quadruple zeta valence quality for $\mathrm{H}$ to $\mathrm{Rn}$ : design and assessment of accuracy. Phys Chem Chem Phys 7: 3297-3305

33. Weigend F (2006) Accurate coulomb-fitting basis sets for $\mathrm{H}$ to $\mathrm{Rn}$. Phys Chem Chem Phys 8:1057-1065

34. Klamt A, Schürmann G (1993) COSMO: a new approach to dielectric screening in solvents with explicit expressions for the screening energy and its gradient. J Chem Soc Perkin Trans 2 1993:799-805

35. Metz B, Stoll H, Dolg M (2000) Small-core multiconfigurationDirac-Hartree-Fock-adjusted pseudopotentials for post-d main group elements: application to $\mathrm{PbH}$ and $\mathrm{PbO}$. J Chem Phys 113: 2563-2569

36. Peterson KA (2003) Systematically convergent basis sets with relativistic pseudopotentials. I. Correlation consistent basis sets for the post-d group 13-15 elements. J Chem Phys 119:11099-11112

37. Pyykkö P (1988) Relativistic effects in structural chemistry. Chem Rev 88:563-594

38. Bae C, Han Y-K, Lee YS (2003) Spin-orbit and relativistic effects on structures and stabilities of group 17 fluorides $\mathrm{EF}_{3}(\mathrm{E}=\mathrm{I}, \mathrm{At}$, and element 117): relativity induced stability for the $D_{3 \mathrm{~h}}$ structure of (117) $\mathrm{F}_{3}$. J Phys Chem A 107:852-858

39. Armbruster MK, Weigend F, van Wüllen C, Klopper W (2008) Self-consistent treatment of spin-orbit interactions with efficient Hartree-Fock and density functional methods. Phys Chem Chem Phys 10:1748-1756
40. Weigend F, Baldes A (2010) Segmented contracted basis sets for one- and two-component Dirac-Fock effective core potentials. J Chem Phys 133:174102/1-10

41. Rappoport D, Furche F (2010) Property-optimized Gaussian basis sets for molecular response calculations. J Chem Phys 133:134105/ $1-11$

42. Cohen AJ, Mori-Sanchez P, Yang W (2012) Challenges for density functional theory. Chem Rev 112:289-320

43. Champagne B, Perpete EA, Jacquemin D, van Gisbergen SJA, Baerends E-J, Soubra-Ghaoui C, Robins KA, Kirtman B (2000) Assessment of conventional density functional schemes for computing the dipole moment and (hyper)polarizabilities of push-pull $\pi$-conjugated systems. J Phys Chem A 104:4755-4763

44. Baranowska-Łączkowska A, Bartkowiak W, Góra RW, Pawłowski F, Zaleśny R (2013) On the performance of long-range-corrected density functional theory and reduced-size polarized LPol-n basis sets in computations of electric dipole (hyper)polarizabilities of $\pi$ conjugated molecules. J Comput Chem 34:819-826

45. Cohen AJ, Tantirungrotechai Y (1999) Molecular electric properties: an assessment of recently developed functionals. Chem Phys Lett 299:465-472

46. Alipour M, Mohajeri A (2013) Assessing the performance of density functional theory for the dynamic polarizabilities of amino acids: treatment of correlation and role of exact exchange. Int $\mathrm{J}$ Quantum Chem 113:1803-1811

47. Hickey AL, Rowley CN (2014) Benchmarking quantum chemical methods for the calculation of molecular dipole moments and polarizabilities. J Phys Chem A 118:3678-3687

48. TURBOMOLE 7.0.1 (2015) A development of University of Karlsruhe and Forschungszentrum Karlsruhe GmbH, 1989-2007, TURBOMOLE GmbH, since 2007. Available from http://www. turbomole.com

49. Steffen C, Thomas K, Huniar U, Hellweg A, Rubner O, Schroer A (2010) TmoleX - a graphical user interface for TURBOMOLE. J Comput Chem 31:2967-2970

50. Modelli A, Guerra M, Jones D, Distefano G, Irgolic KJ, French K, Pappalardo GC (1984) Electron transmission spectra of selenophene and tellurophene and $\mathrm{X} \alpha$ computations of electron affinities for chalcophenes. Chem Phys 88:455-461

51. Hadad CM, Rablen PR, Wiberg KB (1998) C-O and C-S bonds: stability, bond dissociation energies, and resonance stabilization. J Org Chem 63:8668-8681

52. Luttringhaus A, Grohmann J (1955) Über den bindungscharakter der thiongruppe. Z Naturforsch B 10:365-367

53. Huang S, Gronert S, Wu W (2011) Polarization in the structures of uracil and thiouracils: implication for binding with orotidine 50monophosphate decarboxylase. Bioorg Med Chem Lett 21:6341-6342

54. Lumbroso H, Liégeois C, Andrieu CG (1985) Preferred conformations of pivalophenone, (2-pivaloyl)- and (2-aroyl)-furans, (2pivaloyl)- and (2-aroyl)-thiophens, (2-pivaloyl)- and (2-benzoyl)selenophen, and their sulphur analogues. Z Naturforsch A 40: $1338-1348$

55. Braida B, Hiberty PC (2010) Explicit solvation effects on the conventional resonance model for protonated imine, carbonyl, and thiocarbonyl compounds. Int J. Quantum Chem 110:571-577

56. Reichardt C, Welton $\mathrm{T}$ (2011) Solvents and solvent effects in organic chemistry, 4th edn. WILEY-VCH, Weinheim

57. Millefiori S, Alparone A (1998) (hyper)polarizability of chalcogenophenes $\mathrm{C}_{4} \mathrm{H}_{4} \mathrm{X}(\mathrm{X}=\mathrm{O}, \mathrm{S}, \mathrm{Se}, \mathrm{Te})$. Conventional ab initio and density functional theory study. J Mol Struct (THEOCHEM) 431:59-78

58. Atkins P, de Paula J, Friedman R (2009) Quanta, matter, and change: a molecular approach to physical chemistry. Freeman, New York

59. Brinck T, Murray JS, Politzer P (1993) Polarizability and volume. J Chem Phys 98:4305-4306 